\title{
Model selection for waste conversion efficiency and energy demands in a pilot for large-scale larvae treatment
}

\author{
Evgheni Ermolaev ${ }^{1}$ Erik Dahlquist ${ }^{2}$ Cecilia Lalander $^{1}$ Björn Vinnerås ${ }^{1}$ Eva Thorin ${ }^{2}$ \\ ${ }^{1}$ Department of Energy and Technology, Swedish University of Agricultural Sciences (SLU), Sweden, \\ evgheni.ermolaev@slu.se \\ ${ }^{2}$ Department of Energy, Building and Environment, Mälardalen University, Sweden
}

\begin{abstract}
Implementations of conversion systems for segregated food waste into larval biomass are reliant on stability of production environment and predictable outcomes. However, the knowledge is currently lacking for large scale implementation modelling allowing to adjust the process for reaching a stable production quality and predicting the treatment capacity and output product quantity. This study contributed to the development of such knowledge and investigated models for prediction of larvae mass gain in the conversion process, food waste degradation due to larval and microbial activity, heat production based on metabolic activity in the conversion process. These models were used to evaluate the amount of heat produced and compared to the demand for water removal for achieving a minimal total solids content (50\%) in the treatment residue for easy larvae separation by sieving. Based on these models' predictions and measurements of the conversion efficiency it was established that, assuming no heat loss from the system, the heat generated by the process was sufficient to achieve a desirable total solids content in the residue after 14 days of treatment. An exponential heat production from waste degradation can be expected, and thus, for wetter food waste, the treatment period can be expanded to achieve the desired residue total solids content.
\end{abstract}

Keywords: Black soldier fly, degradation, conversion, sieving, food waste, high water content.

\section{Introduction}

Insect rearing for feed production is becoming more enticing in strive to find sustainable and locally produced feed proteins (Kim et al., 2019). Still, the trend globally is that consumption of insects used as feed and food is decreasing, although a recent estimation suggests that some 2.5 billion people occasionally eat insects, mostly in Asia, Africa and Central -South America (Van Huis et al., 2013). Historically, in Europe, the use has been quite low. However, the search for sustainable protein is driving the development of larger facilities producing insects (Makkar, 2017). A great deal of attention has been given to the black soldier fly
(Hermetia illucens) in particular due to its potential for use in organic waste treatment (Čičková et al., 2015). A step-by-step guide for such implementation was recently presented by Dortmans et al. (2017). However, the majority of scientific investigations have so far focused on treatment efficiency in treating different organic waste fractions, and very few studies focus on large-scale production optimization (Mertenat et al., 2019). Other studies by Leong et al. (2016) and Li et al. (2011) investigated bio diesel production potential, while Pastor et al. (2015) and (Spranghers et al., 2017) have studied bottlenecks in conversion processes.

The success of large-scale insect biomass production system implementation is reliant on stability of production environment with predictable output quantities and quality of larvae and residue (Čičková et al., 2015). Such a system can be easily scaled to the expected amount of substrate and appropriate adjustments can be made with known effects on outcomes depending on the amounts of products needed or substrate to be treated. Such stability has to be achieved by insect farmers at European and global level in order to meet future demands for protein (IPIFF, 2018). The use of organic waste as a source for production of larvae with intent for animal feed or biodiesel production has been evaluated in several studies (Leong et al., 2016; Li et al., 2011; Pastor et al., 2015; Spranghers et al., 2017). The grown black soldier fly (BSF) larvae are high in fat, containing $20-50 \%$ of fat on a dry matter basis. Protein content is typically in the range of $35-42 \%$ on a dry matter basis (Ewald, 2019; Lalander et al., 2019). Such composition of larval biomass represents a great source of protein and fat for production of animal feed.

For large scale implementation, several parameters are important to establish a stable production. Such parameters include the dimensioning of the number of fly larvae per amount of treated substrate, process temperature and retention time in treatment (Diener et al., 2011; Liu et al., 2017; Paz et al., 2015; Tomberlin et al., 2009). Another important parameter often discussed is achieving a moisture content in the treatment residue that allows dry separation of larvae after the treatment. Cheng et al. (2017) has investigated how larvae 
separation is affected by moisture content in the residue. The initial tests performed at the pilot plant at Eskilstuna Strängnäs Energi och Miljö collaborating in the current project have shown that total solids content of the residue above $40-45 \%$ allows an easy larvae separation through sieving.

The aim of this study was to evaluate the technical aspects of larvae growth, ventilation and drying in a pilot sized BSF treatment system treating segregated household food waste and to develop mathematical models to describe the treatment process and its energy efficiency.

\section{Material and methods}

This section contains details about the study set up, materials and methods used, measurement techniques and assumptions.

\subsection{Description of the larvae production facility in Eskilstuna}

The measurements were performed at the fly larvae conversion pilot facility at Eskilstuna Strängnäs Energi och Miljö, while process efficiency evaluations were performed both at the pilot facility and at the Swedish University of Agricultural Sciences (SLU).

\subsubsection{Treatment set-up}

The treatment process began when approximately 15000 seven-day-old larvae were added to a treatment box containing the first feeding portion of $5 \mathrm{~kg}$ waste (Figure 1A). The treatment boxes had a surface area of $2400 \mathrm{~cm}^{2}$ (Figure 1). Treatment boxes were stacked by 8 , and four such stacks were started approximately once per week. The boxes were stacked in order to increase treatment volume. The stacks were placed in a treatment room which was heated using residual heat at the Eskilstuna waste management facility. Three sets of stacks (4 in each) were evaluated. The sets were named T20, T11 and T5 indicating how many days they were in the treatment on the day when temperature and relative humidity $(\mathrm{RH})$ were measured. Four boxes were sampled in each set. The boxes were fed with two additional $5 \mathrm{~kg}$ portions of food waste with an interval of 3-6 d (Table 1). After the last feeding the material was left for 5-14 d to be processed by the larvae. On day 1421 from treatment start, the larvae were separated from the residue using a rotating drum sieve.

\subsubsection{Materials}

The young larvae were produced at SLU from a continuously run BSF colony since 2015. The sevenday-old larvae were pre-weighed to contain approximately 15000 based on a smaller sample that was determined by enumeration and a gravimetric estimation of a single larvae weight.

The segregated household food waste, which was collected in plastic bags and went through optical sorting process, subsequently was minced in an extruder-grinder that also separated out plastic and other fractions not passing through the mesh.

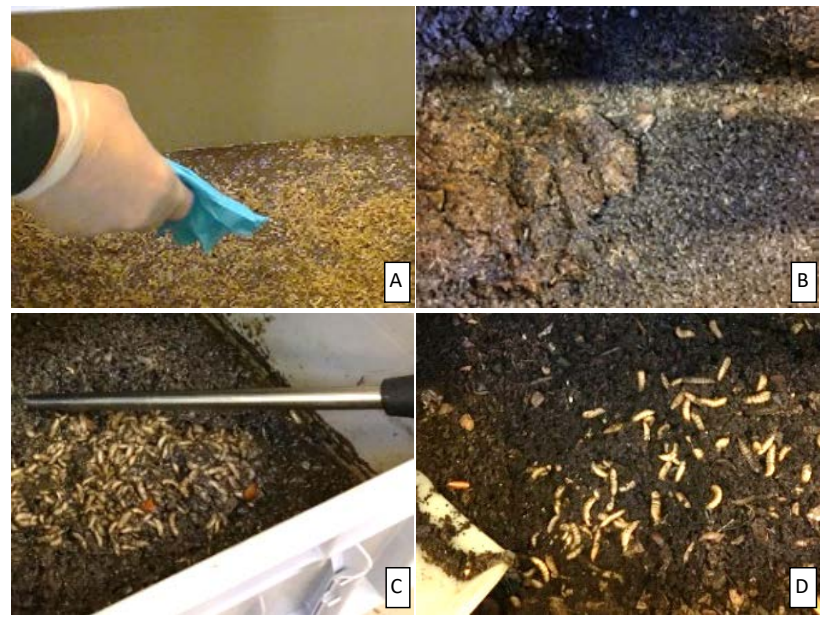

Figure 1. Depiction of larval growth and visual material changes during treatment process a) at start of treatment, b) after 5 days of treatment, c) after 11 days of treatment and d) after 20 days of treatment.

\subsubsection{Temperature and moisture sampling}

Temperature was sampled using a Fluke pyrometer to measure surface temperature. For the temperature in the material (below the surface), approximately $10 \mathrm{~mm}$ of material top layer was removed and the temperature measured directly. The temperature and relative humidity (RH) were sampled using a Testo 400 thermohygrometer probe to measure temperature and $\mathrm{RH}$ values in the material and right at the surface of material. The measurements were performed in boxes kept at different heights in the stacks and different locations at the facility. For each box, 5-7 sub-samples were collected in random positions and an average value was used as a reading, but multiple replicate boxes were

Table 1. Treatment schedule showing the age of stacks with treatment boxes in days from start (ST) to sampling day (highlighted in green). First feeding was provided at start (highlighted orange) and additional feedings were given within 3-6 days (highlighted blue).

\begin{tabular}{|c|c|c|c|c|c|c|c|c|c|c|c|c|c|c|c|c|c|c|c|c|c|}
\hline Stack set & \multicolumn{21}{|c|}{ Treatment days } \\
\hline T20 & ST & 1 & 2 & 3 & 4 & 5 & 6 & 7 & 8 & 9 & 10 & 11 & 12 & 13 & 14 & 15 & 16 & 17 & 18 & 19 & 20 \\
\hline T11 & & & & & & & & & & ST & 1 & 2 & 3 & 4 & 5 & 6 & 7 & 8 & 9 & 10 & 11 \\
\hline T5 & & & & & & & & & & & & & & & & ST & 1 & 2 & 3 & 4 & 5 \\
\hline
\end{tabular}


compared to ensure reliability of measurements ( $\mathrm{n}=9$ for temperature and $n=4$ for surface humidity).

\subsection{Modelling}

Microbial waste degradation was modeled according to a first order rate expression for microbial oxidation of degradable volatile solids highlighted by Hamelers (2004) and developed by Keener et al. (1992) (1). Similar models based on rate constants, amount of degradable material and environmental factors such as process temperature have been discussed by others e.g. Haug (1993).

$$
\frac{d m}{d t}=-k\left(x_{1}, x_{2}, \cdots x_{n}\right) \cdot\left[m-m_{e}\right]
$$

Where $m$ is the compost mass, $t$ is time, $k$ is the composting process rate constant, $x_{i}$ are the environmental factors e.g. process moisture and temperature and $m_{e}$ is the non-degradable mass of compost at the end of the process.

Larval waste reduction was modelled based on several variables, including bioconversion ratio (BCR) representing the amount of volatile solids (VS) in substrate that has been converted to larval biomass (2).

$$
B C R_{V S}=\frac{V S_{\text {larvae }}}{V S_{\text {substrate }}}
$$

The mass of substrate lost in the process is expressed through a reduction (RED) variable which can be calculated on volatile solids basis, total solids (TS) basis and wet weight (WW) basis. The latter accounts for all the losses in the process including evaporation and respiration (3).

$$
R E D_{w w}=1-\frac{W W_{\text {larvae }}+W W_{\text {residue }}}{W W_{\text {substrate }}}
$$

The larval metabolic activity, along with that performed by microbes, results in respiration, energy release and volatile solids reduction in the substrate. Typically such activity can be associated to the body mass and thus the substrate VS reduction by larvae can be expressed through an adapted model proposed by Wotton (1978) where respiration rate (measured as $\mathrm{C}$ loss from substrate through $\mathrm{CO}_{2}$ emission) is assumed to be proportional to VS loss (4).

$$
\log \frac{d V S_{\text {lost }}}{d t}=a+b \cdot \log M_{\text {larva }}
$$

Where $V S_{\text {lost }}$ represents the amount of substrate VS being lost due to larval metabolic activity over time $t$, $M_{\text {larva }}$ is the individual larvae body mass at time [t] in the process, while parameters $a$ and $b$ represent the initial VS loss rate and the influence degree of the body mass on VS loss rate, respectively. An additional pathway for VS loss is associated to substrate assimilation by the larvae and can be calculated based on BCRvs.

\subsection{Assumptions}

Several parameters used in modelling and evaluations of system productivity were estimated based on previous analyses, studies and published sources. Eskilstuna food waste moisture content has been evaluated in several studies including a study by Johannesdottir (2017) and Lindberg (2018) and the TS range reported was 15\% $23 \%$. Based on these results, communication with Eskilstuna facility operators and measurements performed in the lab (data not shown), it was assumed that the typical TS content of the slurry was $16 \% \pm 2 \%$. Food waste from Eskilstuna have been demonstrated to have a very good $\mathrm{BCR}_{\mathrm{TS}}$ the values reported range between 24 and 32\% (Johannesdottir, 2017; Lindberg, 2018) and in the current system investigation a value of $\mathrm{BCR}_{\mathrm{TS}}$ of $30 \%$ was assumed. Reduction of substrate VS depends on multiple parameters and system dimensioning; however, an assumption is necessary in order to estimate the amount of water needed to be removed in the treatment process. Although a reduction in the range of 56 - 65\% (Johannesdottir, 2017) have been reported for Eskilstuna food waste, a lower RED $\mathrm{TS}_{\mathrm{TS}}$ of $50 \%$ was assumed here in order to not overestimate the amount of energy released from the process typically associated with reduction of substrate.

Based on these values the mass balance of the process can be presented. Per ton of food waste processed, the substrate TS represent 140-180 kg, which assuming a $\mathrm{BCR}_{\mathrm{TS}}$ of $30 \%$ and a $\mathrm{RED}_{\mathrm{TS}}$ of $50 \%$, results in production of 43-55 kg TS of larval biomass and 72-93 $\mathrm{kg}$ TS of treatment residue. Based on these assumptions, the demand to obtain the residue with 50\% TS to allow sieving, the assumption that larvae have TS of $35 \%$ (Johannesdottir, 2017) and the overall mass balance, $709-625 \mathrm{~kg}$ of initial substrate water has to be removed and 25-32 kg of initial TS are respired.

The amount of energy released in the degradation process was estimated based on heat of combustion of biodegradable VS. Mason (2009) calculated that for food waste $5.4 \mathrm{kWh}$ of energy can be released per $\mathrm{kg}$ VS degraded. Based on this assumption the amount of heat released was calculated taking into account the VS content of the food waste slurry (He et al., 2013).

The incoming air to the facility was warmed up to approximately $30{ }^{\circ} \mathrm{C}$ and it was assumed it had $15 \mathrm{RH} \%$ at that temperature based on measurements performed earlier (data not shown). The outgoing air was assumed to be $30{ }^{\circ} \mathrm{C}$ and have an $\mathrm{RH}$ of $95 \%$. Such high saturation level was not achieved in a previous study permed in controlled lab conditions (Johannesdottir, 2017) when a saturation of $61 \mathrm{RH} \%$ was observed in outgoing air. Nevertheless, by adjusting the ventilation rates, nearly full saturation of air can be achieved (Bach et al., 1987), and thus this assumption was used in the current evaluation (Kubilay and Kucska, 2018). Based on these assumptions a water carrying capacity of air was calculated using steam tables (Mörtstedt and 
Hellsten, 1976). It was estimated that $0.022 \mathrm{~kg}$ water can be removed per kg air supplied by the ventilation.

\section{Results and discussion}

\subsection{Treatment process}

The treatment process has been running for 5,11 and $20 \mathrm{~d}$ on the day of moisture sampling. The treatment running for $5 \mathrm{~d}$ (T5 in Table 1, Figure 1B) had larvae that were approximately $10 \mathrm{~mm}$ long (visual estimation) but very thin. In the treatment T11, running for 11 days (Figure 1C) the larvae were larger, visually estimated to be approximately $15 \mathrm{~mm}$ long, but smaller in diameter (by ca $2.5-3 \mathrm{~mm}$ ) than the ones in treatment for 20 days (Figure 1D), which were estimated to have a diameter around 3.5 - $4 \mathrm{~mm}$ and were approximately $20 \mathrm{~mm}$ long. The moisture content in the material was relatively high after 11 days of treatment, and as seen in the picture in Figure $1 \mathrm{~B}$, the treatment surface appeared wet. Figure 1D shows the larvae that had treated the material for 20 days. The waste was dried to a TS content of approximately or lower than $50 \%$ due to biological activity generating heat that was driving evaporation together with ventilation.

The facility had a treatment capacity for $1440 \mathrm{~kg}$ of material at any given time, however as the material was added in portions, on the sampling day there was $960 \mathrm{~kg}$ of material being treated. Only stacks in the treatment T20 reached the full capacity as they were fed 3 times (Table 1). The average capacity for the facility considering the feeding frequency and treatment duration of 21 days was $69 \mathrm{~kg}$ waste/d, however the capacity could be increased to $103 \mathrm{~kg}$ waste/d if a shorter treatment time was used. The available space was not fully utilized, and the design goal was to reach a treatment capacity of $1000 \mathrm{~kg} / \mathrm{d}$, which would be possible if the process was run during 14 days per batch and all potential treatment volume was used.

During this evaluation, the pilot fly larvae treatment facility in Eskilstuna used stacked treatment units (boxes) each treating $15 \mathrm{~kg}$ of food waste. Each unit after $14 \mathrm{~d}$ of treatment produced approximately $2.4 \mathrm{~kg}$ of larvae and $2.5 \mathrm{~kg}$ residue (based on initial TS and VS evaluations performed in the lab and assuming a BCR $\mathrm{BS}_{\mathrm{TS}}$ of $30 \%$ and $\mathrm{RED}_{\mathrm{TS}}$ of $50 \%$, data not shown). The estimation of the process performed in the lab (based on TS and VS measurements of substrate and treatment products, data not shown) on dry solids basis gave $1.0 \pm$ $0.2 \mathrm{~kg}$ larvae and $1.0 \pm 0.1 \mathrm{~kg}$ residue and a mass loss due to metabolism of $0.5 \pm 0.1 \mathrm{~kg}$ TS (variations assumed based on expected variation in moisture content in the incoming material). On the measurement day a total of 11 treatment units were sampled with respect to temperature and relative humidity (T5, T11 and T20) from the three treatments sets (Figure 2).

The difference in temperature below the surface (in material) and at the material surface was approximately $0.5^{\circ} \mathrm{C}$ for T5, while it was $2{ }^{\circ} \mathrm{C}$ for $\mathrm{T} 11$ and $2.7^{\circ} \mathrm{C}$ for T 20 (c.f. standard deviations Figure 2). This shows that the longer treatment process was, the higher heat generation was observed, increasing the temperature inside the material and causing larger difference in surface temperature.

\subsection{Modelling}

Several processes can be modeled in this system implementation that should follow standard models, including larval and microbial growth, energy generation in the process and water loss from material due to evaporation and ventilation. The general microbial and larval waste degradation models are presented in the methods section (1 and 4). The larval degradation model uses larval mass as a parameter for estimation of degradation (4). It is thus important to evaluate the larvae growth and develop a model for its characterization.

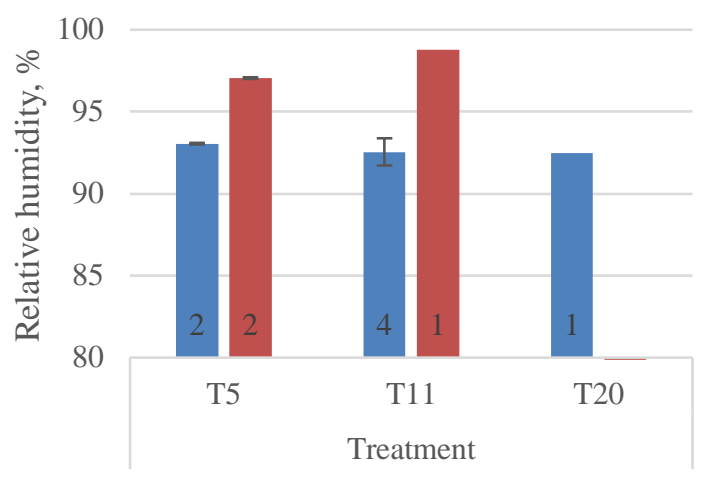

$\square \mathrm{RH}$ at material surface $\quad$ RH in material

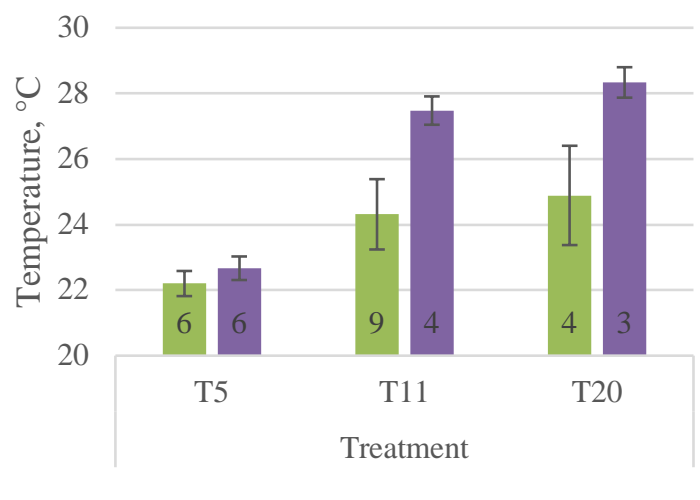

$\mathrm{T}$ at material surface $\quad \mathrm{T}$ in material

Figure 2. Graphical representation of a) \%RH and b) temperature ( $\mathrm{T})$ on the measurement day in different treatments, whiskers (where available) show standard deviation and numbers inside bars show $n$. Measurement of $\mathrm{T}$ b) and \%RH a) in boxes using pyrometer (T1) from Fluke and T (T2) and RH\% using Testo 400.

\subsubsection{Larvae growth and material reduction}

The BSF larvae growth have been evaluated in multiple studies (Diener et al., 2011; Lalander et al., 2019) 
showing that larvae grow nearly linearly, but there is a slightly slower growth rate at the beginning of the process. This suggests that an exponential growth model could fit well to describe the first period of larvae growth during the first 10-14 days (5).

$$
x_{d+1}=x_{d}+a * t^{b}
$$

Were $x_{d+1}$ is the weight of larvae at next time step (next day, $d+1), x_{d}$ the weight at current time step (current day, $d$ ), $a$ is a constant expressing the larvae mass gain rate, $t$ is the accumulated time, in hours since the growth started and $b$ is another constant expressing the larvae mass gain rate change with time. Constants $a$ and $b$ include environmental impacts of the system on larval growth. When the equation was fitted to achieve the expected larvae size in treatment over 10-14 days based on assumptions described in section 1.1.3, the constants $a$ and $b$ had values of 0.12 and 0.8 , respectively, while $a$ value became 0.15 when the treatment duration was set to 21 days. In this case assuming the treatment started with $160 \mathrm{~kg}$ TS in waste and after 14 days produced $49 \mathrm{~kg}$ larvae TS. The conversion efficiency (BCRTS) in this case became $(49 * 100 \%) / 160=30,6 \%$. Such a BCR BS $_{\text {TS }}$ value represents a very good conversion ratio since the normal range is between $25-36 \%$ for different types of substrates (Lalander et al., 2019). Such a BCR range for food waste would result in 41- $59 \mathrm{~kg}$ larvae from the original $0.25 \mathrm{TS} \mathrm{kg}$ young larvae and $160 \mathrm{~kg}$ TS waste.

It was observed by Lalander et al. (2019) that the BSF larvae grow mostly during the first two weeks of treatment, but then the additional weight gain is small during the third week, or even a weight reduction was observed. Such a development is associated with BSF life cycle: if the larvae have reached their target larval stage and become pre-pupae, they no longer feed and thus only consume stored fat and protein necessary for their metabolism, movement and metamorphosis. A further investigation of larvae growth based on a study by Lalander et al. (2019), showed that the growth rate is slow in the beginning of treatment of food waste, but then accelerates and peaks during days 4 to 9 . After this, the growth rate decreases, and after day 12 (for most substrates) the larvae mass increase stops (Figure 3). When further increase in larvae mass stopped, but larvae have not yet reached the pre-pupae stage (days 12-14) the waste was degraded due to metabolism, but it did not give increased growth resulting in unchanged BCR and increased RED. After 3 weeks in treatment, the larvae start pupating, which causes an additional weight loss as they have stopped eating already in the pre-pupae stage. The peak weight gain and the duration of weight gain period was observed to differ between the substrates, but for food waste, the peak could be expected around day 7 (based on model projection and data from Lalander et al., 2019) under optimal conditions (Figure 3). This means the exponential model (5) well describes the beginning of the process, but to cover the whole treatment time a cumulative distribution function fits better and matches with the data points presented in Lalander (2019).

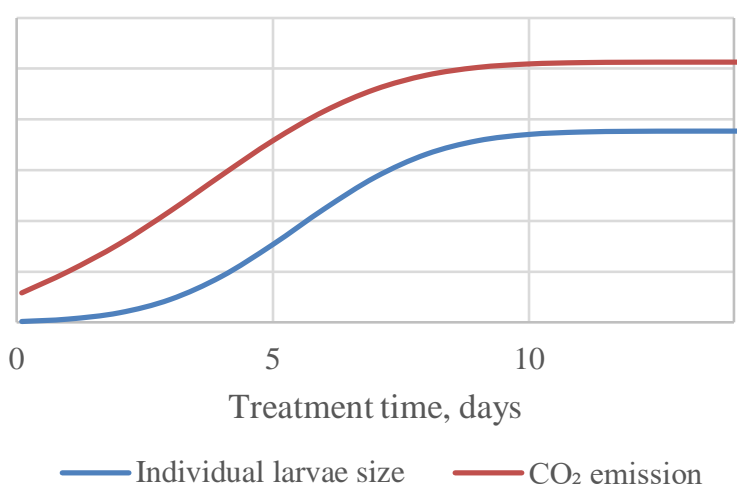

Figure 3. Graphical (dimensionless) representation of larvae weight change as a function of time for 1 ton food waste with $16 \%$ TS fed during 14 days and an associated $\mathrm{CO}_{2}$ emission rate based on VS loss due to larval metabolism (4).

When comparing the actual weight curve to an exponential curve it was found that it fitted fairly well the first 10 days, but after that the larval growth stopped as the larvae reached their maximum weight (Figure 3). From a production perspective thus, a shorter harvest after approximately 10 days should be evaluated to maximize the output of larval biomass. Such shorter treatment can result in insufficient water removal from material (treatment residue) which needs to be sufficiently dry to enable separation of larvae (Cheng et al., 2017). In this pilot set-up, the mixture was still quite wet after $10 \mathrm{~d}$ and it would not have been possible to efficiently separate the larvae from the treatment residue. If the larvae are left in the material for longer, their and microbial metabolisms further reduce the substrate, which can result in additional water evaporation due to associated heat generation. Such reduction can be modeled using equations 1 and 4 described earlier. According to these models and the model for larvae growth (5), the larvae and microbial metabolic rates increase exponentially and thus the energy release from metabolism also increases exponentially during exponential larval growth.

In the beginning of treatment, the bioconversion rate is low which means that heat generation is low, and the food waste slurry is still very high in water content. In parallel with larval digestion of food waste a microbial process also takes place. A first order exponential or linear model for aerobic food waste degradation can describe such a microbial process well (Hamelers, 2004). Thus, in the beginning of the treatment due to lag in larvae growth the decrease in moisture content was marginal, and likely mainly due to microbial activity. As the larval mass increased, the larval activity also 
increased, resulting in a substantial heat release and evaporation of water. If the treatment is allowed to continue beyond the typical $14 \mathrm{~d}$ until $21 \mathrm{~d}$, the larva first become prepupae and then turn into pupae, meaning they no longer degrade the substrate. However the microbial waste degradation continues and provides additional heat necessary for water evaporation from the residue.

The amount of waste that was converted into heat can be calculated based on oxidation reaction of the average food waste formula, resulting in production of energy and of $\mathrm{CO}_{2}+\mathrm{H}_{2} \mathrm{O}$. The amount of food waste oxidized was estimated based on degradation rate, $\frac{d m_{\text {waste }}}{d t}$ and was calculated from multiplying the mass of larvae, $m_{l}$, by the degradation per kg larvae for each day, $A_{l}$, and the same for microorganisms $\left(m_{m o}, A_{m o}\right)$. As the accumulated larval and microbial biomass increases, the absolute degradation per day also increases (6).

$$
\frac{d m_{\text {waste }}}{d t}=m_{\text {waste }} *\left(m_{l} * A_{l}+m_{m o} * A_{m o}\right)
$$

The accumulated heat release from TS degradation can also be presented as a function of time. Assuming $0.25 \mathrm{~kg}$ TS of young larvae was originally added to 160 $\mathrm{kg}$ TS waste and using an assumption that $5.4 \mathrm{kWh}$ is released per $\mathrm{kg}$ TS respired (Mason, 2009), the total energy release can be estimated. Based on the assumptions made earlier in methods section 1.1.3, an evolution of $449 \mathrm{kWh}$ can be assumed after 10 days or accumulated $807 \mathrm{kWh}$ after 14 days.

\subsubsection{Evaporation of water to dry the waste}

The waste slurry used in the process in this pilot set-up was relatively high in water content ( 16\% DM), assuming that the facility would process 1 ton waste per day, $160 \mathrm{~kg}$ TS/d would also bring $840 \mathrm{~kg}$ water/d. To separate larvae from the residue, the treatment residue should reach around 50\% TS (Cheng et al., 2017). Taking into account the material reduction of 50\%, 72 $93 \mathrm{~kg}$ water would be remaining in the residue after 14 days of treatment, equivalent to 625 - $709 \mathrm{~kg}$ water needed to be evaporated per day. The heat released by the larvae estimated above was $449 \mathrm{kWh}$ during the first 10 days but $807 \mathrm{kWh}$ after 14 days. For removal of one $\mathrm{kg}$ water it is required $0.628 \mathrm{kWh}$ of heat for evaporation. Assuming that only the heat evolved from the degradation of the waste would be used for evaporation and there was no other heat loss, the total amount of water evaporated could be 449/0.628 = 715 $\mathrm{kg}$ water. This roughly corresponds to an original moisture content of $16 \%$ TS. If more water needs to be evaporated, additional heat has to be supplied (from the ventilation air), or the process should be allowed to continue for longer. Two extra days would yield additional $179 \mathrm{kWh}$, which would be enough to achieve desired residue TS if the original TS of the waste slurry was $13.8 \%$.
The BSF larvae generally move quite actively, the amount of heat generated due to this motion is also expected to be proportional to the larvae size up until the pre-pupae stage, when larvae start behaving differently. This makes the selection of optimal time for harvest relevant for optimizing the protein production and total yield, while avoiding the unnecessary losses due to metabolic activity not resulting in further larvae mass gain. The harvest period should be extended by approximately one more week (beyond the usual 14 days), if pupae are required for e.g. fly production to maintain a BSF colony and produce eggs. This was the case for the pilot set-up evaluated in this study.

In case the generated metabolic heat is insufficient for evaporation, the heat energy from heated ventilation air could be used to remove excess water from the substrate. Assuming the incoming ventilation air had a temperature of $30{ }^{\circ} \mathrm{C}$ with a $\mathrm{RH}$ of $15 \%$ and the outgoing air was saturated to a $\mathrm{RH}$ of $95 \%$ at $30{ }^{\circ} \mathrm{C}, 0.022 \mathrm{~kg} \mathrm{H}_{2} \mathrm{O}$ could be removed per $\mathrm{kg}$ air. To remove a total of 715 $\mathrm{kg}$ water the demand at such conditions would be 32500 $\mathrm{kg}$ air which would be equivalent to ventilation rate of $85 \mathrm{~m}^{3} / \mathrm{h}$. The ventilation fan at Eskilstuna pilot facility was estimated to provide airflow over $700 \mathrm{~m}^{3} / \mathrm{h}$ suggesting a quicker than observed water removal would be expected. However, the ventilation air was not directed in a way to maximize its saturation and thus likely contributed to evaporation to a smaller degree.

Previous studies on a similar system also highlighted that a better air saturation would improve water removal rate from such fly larvae conversion system that was mostly relying on heat release associated with degradation process for water evaporation (Johannesdottir, 2017; Kubilay and Kucska, 2018).

\section{Conclusions}

Based on the results obtained from the pilot scale treatment facility and the experiments performed in laboratory environment it was possible to model the black soldier fly larvae development and the associated waste degradation rate attributed to both larval and microbial metabolism. Based on these models' predictions and measurements of the conversion efficiency it was established that, assuming no heat loss from the system, the heat generated by the process was sufficient to achieve a desirable total solids content in the residue after 14 days of treatment. An exponential heat production from waste degradation can be expected, and thus, for wetter food waste, the treatment period can be expanded to achieve the desired residue total solids content.

Using the models presented in this study and based on environmental properties of the treatment and waste type and moisture content, it is possible to project if the amount of heat generated by the waste reduction during the treatment is going to be sufficient to remove the amount of water to achieve a sievable residue (reaching 
total solids content of 50\%). After the necessary calibration of the models for each particular system, they can be used as tools for deciding the duration of treatment and the amount of heat supplied by the ventilation.

\section{Acknowledgements}

We thank Eskilstuna Strängnäs Energi och miljö for their support in implementation of the pilot project, Naturvårdsverket and Swedish University of Agricultural Sciences (SLU) for the financial support of this project.

\section{References}

P.D. Bach, K. Nakasaki, M. Shoda, and H. Kubota. Thermal balance in composting operations. Journal of Fermentation Technology, 65(2): 199-209, 1987. doi: 10.1016/0385-6380 (87)90165-8.

J.Y.K. Cheng, S.L.H. Chiu, and I.M.C. Lo. Effects of moisture content of food waste on residue separation, larval growth and larval survival in black soldier fly bioconversion. Waste Management, 67: 315-323, 2017. doi: 10.1016/j.wasman.2017 .05.046.

H. Čičková, G.L. Newton, R.C. Lacy, and M. Kozánek. The use of fly larvae for organic waste treatment. Waste Management, 35: 68-80, 2015. doi: 10.1016/j.wasman.2014.09.026

S. Diener, N.M.S. Solano, F.R. Gutierrez, C. Zurbrugg, and K. Tockner. Biological Treatment of Municipal Organic Waste using Black Soldier Fly Larvae. Waste and Biomass Valorization, 2(4): 357-363, 2011. doi: 10.1007/s12649-0119079-1.

B. Dortmans, S. Diener, B. Verstappen, and C. Zurbrügg. Black soldier fly biowaste processing: a step-by-step guide. Eawag, Sandec, Dübendorf, Switzerland, 2017.

N. Ewald. Fatty acid composition of black soldier fly larvae impact of the rearing substrate. Master Thesis. Department of Energy and Technology, Swedish University of Agricultural Sciences, Uppsla, 2019.

H.V.M. Hamelers. Modeling composting kinetics: A review of approaches. Reviews in Environmental Science and Bio/ Technology, 3(4): 331-342, 2004. doi: 10.1007/s11157-0042335-0.

R.T. Haug. The Practical handbook of compost engineering. Lewis Publishers, Boca Raton, Florida, FL, USA, 1993. doi: 10.1201/9780203736234.

P.J. He, L. Zhao, W. Zheng, D. Wu, and L.M. Shao. Energy Balance of a Biodrying Process for Organic Wastes of High Moisture Content: A Review. Drying Technology, 31(2): 132145, 2013. doi: 10.1080/07373937.2012.693143.

IPIFF. The European Insect Sector Today: Challenges, Opportunities and Regulatory Landscape. IPIFF vision paper on the future of the insect sector towards 2030, IPIFF, 2018.

S. Johannesdottir. Uppskalning av fluglarvskompostering: Luftningsbehov och ventilation. Master Thesis. Department of Energy and Technology, Swedish University of Agricultural Sciences, Uppsla, 2017.

H. Keener, R. Hansen, and C. Marugg. Optimizing the efficiency of the composting process. In Proceedings of the International Composting Research Symposium. Renaissance Publications, Columbus, OH, 1992.

S.W. Kim, J.F. Less, L. Wang, T.H. Yan, et al. Meeting Global Feed Protein Demand: Challenge, Opportunity, and Strategy.
Annual Review of Animal Biosciences, 7: 221-243, 2019. doi: 10.1146/annurev-animal-030117-014838.

K. Kubilay and K. Kucska. Energi och ventilation vid biomassaproduktion av larver: Optimering av ett ventilationssystem med hjälp av beräkningsmodell i Excel för containern i demoanläggningen, i Lilla Nyby. Master Thesis. School of Business, Society and Engineering, Mälardalen University, Västerås, 2018.

C. Lalander, S. Diener, C. Zurbrügg, and B. Vinnerås. Effects of feedstock on larval development and process efficiency in waste treatment with black soldier fly (Hermetia illucens). Journal of Cleaner Production, 208: 211-219, 2019. doi: 10.1016/j.jclepro.2018.10.017.

S.Y. Leong, S.R.M. Kutty, A. Malakahmad, and C.K. Tan. Feasibility study of biodiesel production using lipids of Hermetia illucens larva fed with organic waste. Waste Management, 47: 84-90, 2016. doi: 10.1016/j.wasman.2015.03 .030 .

Q. Li, L.Y. Zheng, H. Cai, E. Garza, et al. From organic waste to biodiesel: Black soldier fly, Hermetia illucens, makes it feasible. Fuel, 90(4): 1545-1548, 2011. doi: 10.1016/j.fuel .2010.11.016.

L. Lindberg. Utsläpp av växthusgaser och ammoniak under fluglarvskompostering. Master Thesis. Department of Earth Sciences, Uppsala University, Uppsala, 2018.

X. Liu, X. Chen, H. Wang, Q.Q. Yang, et al. Dynamic changes of nutrient composition throughout the entire life cycle of black soldier fly. PLoS One, 12(8), 2017. doi: 10.1371/journal.pone .0182601 .

H.P.S. Makkar. Review: Feed demand landscape and implications of food-not feed strategy for food security and climate change. animal, 1-11, 2017. doi: 10.1017/S175173111 700324X.

I.G. Mason. Predicting biodegradable volatile solids degradation profiles in the composting process. Waste Management, 29(2): 559-569, 2009. doi: 10.1016/j.wasman.2008.05.001

A. Mertenat, S. Diener, and C. Zurbrügg. Black Soldier Fly biowaste treatment - Assessment of global warming potential. Waste Management, 84: 173-181, 2019. doi: 10.1016/j.wasman .2018.11.040.

S.-E. Mörtstedt and G. Hellsten. Data och diagram: energi- och kemitekniska tabeller. Esselte Studium, Stockholm, 1976.

B. Pastor, Y. Velasquez, P. Gobbi, and S. Rojo. Conversion of organic wastes into fly larval biomass: bottlenecks and challenges. Journal of Insects as Food and Feed, 1(3): 179-193, 2015. doi: 10.3920/ JIFF2014.0024.

A.S.P. Paz, N.S. Carrejo, and C.H.G. Rodriguez. Effects of Larval Density and Feeding Rates on the Bioconversion of Vegetable Waste Using Black Soldier Fly Larvae Hermetia illucens (L.), (Diptera: Stratiomyidae). Waste and Biomass Valorization, 6(6): 1059-1065, 2015. doi: 10.1007/s12649-0159418-8.

T. Spranghers, M. Ottoboni, C. Klootwijk, A. Ovyn, et al. Nutritional composition of black soldier fly (Hermetia illucens) prepupae reared on different organic waste substrates. Journal of the Science of Food and Agriculture, 97(8): 2594-2600, 2017. doi: 10.1002/jsfa.8081.

J.K. Tomberlin, P.H. Adler, and H.M. Myers. Development of the Black Soldier Fly (Diptera: Stratiomyidae) in Relation to Temperature. Environmental Entomology, 38(3): 930-934, 2009. doi: 10.1603/022.038.0347.

A. Van Huis, J. Van Itterbeeck, H. Klunder, E. Mertens, et al. Edible insects: future prospects for food and feed security. Food and Agriculture Organization of the United Nations, 2013.

R.S. Wotton. Growth, Respiration, and Assimilation of Blackfly Larvae (Diptera Simuliidae) in a Lake-Outlet in Finland. Oecologia, 33(3): 279-290, 1978. doi: 10.1007/Bf00348114. 